\title{
PENGARUH GAYA KEPEMIMPINAN DAN BUDAYA ORGANISASI TERHADAP KINERJA MANDOR KEBUN DENGAN KEPUASAN KERJA SEBAGAI VARIABEL INTERVENING
}

\author{
Prakasa Hernanta ${ }^{a}$ \\ Dwi Ratmawati ${ }^{\text {b }}$ \\ ${ }^{a}$ Sekolah Pascasarjana Universitas Airlangga ${ }^{\mathrm{b}}$ Fakultas Ekonomi dan Bisnis Universitas Airlangga \\ Email: prakasa.h@protonmail.com ${ }^{a}$; dwi.ratmawati@feb.unair.ac.id ${ }^{b}$
}

\section{ARTICLE HISTORY}

Received:

19 July 2018

Revised

29 August 2018

Accepted:

18 September 2018

Online available:

10 November 2018

Keywords (Calibri 10):

leadership styles, organizational culture, performance, job

satisfaction

Kata Kunci:

gaya kepemimpinan, budaya organisasi, kinerja, kepuasan kerja

*Correspondence:

Name:

E-mail: ........

\begin{abstract}
Introduction: This study aimed to analyze the influence of leadership styles and organizational culture on the performance of plantation foremen as the first responsible person in the field with job satisfaction as an intervening variable.

Methods: To examine these issues, a questionnaire distributed at 35 plantation foreman Semboro Sugar Factory. The collected data is then analyzed using the technique of partial least squares analysis using smartPLS 2.0.
\end{abstract}

Results: Indicated that leadership style is positively and significantly affect performance. Organizational culture is also positive and significant effect on performance. Leadership style is positively and significantly affect performance either directly or indirectly through job satisfaction, and organizational culture in a positive and significant effect on performance, both directly and indirectly through job satisfaction.

Conclusion and suggestion: Managerial suggestion is to apply nurturant leadership style and task oriented style. More is to creat and maintain the plantation foreman involvement in the culture of the organization, in line with the giving level of job satisfaction perceived by the plantation foreman that will ultimately improve the performance of the plantation foreman hopes of reaching the production of sugarcane per hectare according to the potential of existing varieties. 


\begin{abstract}
ABSTRAK
Adanya pemimpin muda baru khususnya jurusan penanaman dalam dua tahun terakhir memberikan corak kepemimpinan yang beragam di PG Semboro. Pada saat yang bersamaan, direksi menyusun kembali dan memperkenalkan visi, misi dan budaya organisasi. Dalam kurun waktu tersebut pula, kinerja Dinas Penanaman Pabrik Gula Semboro terlihat menunjukkan pencapaian tertinggi sejak diberlakukannya sistem peleburan karbonatase dalam tonase dan rendemen tebu, namun dari segi produksi per hektar belum mampu mencapai potensi yang semestinya. Belum tercapainya potensi produksi per hektar merupakan masalah evaluasi bagi manajemen untuk mendapatkan nilai tambah yang lebih. Oleh karena itu, penelitian ini bertujuan untuk menganalisis pengaruh gaya kepemimpinan dan budaya organisasi terhadap kinerja mandor perkebunan sebagai penanggung jawab pertama di lapangan dengan kepuasan kerja sebagai variabel intervening.

Untuk meneliti hal tersebut, dilakukan penyebaran kuisioner pada 35 mandor perkebunan Pabrik Gula Semboro. Data yang terkumpul kemudian dianalisis dengan menggunakan teknik analisis kuadrat terkecil parsial menggunakan smartPLS 2.0. Hasil penelitian ditemukan bahwa gaya kepemimpinan berpengaruh positif dan signifikan terhadap kinerja. Budaya organisasi juga berpengaruh positif dan signifikan terhadap kinerja. Gaya kepemimpinan berpengaruh positif dan signifikan terhadap kinerja baik secara langsung maupun tidak langsung melalui kepuasan kerja, dan budaya organisasi berpengaruh positif dan signifikan terhadap kinerja, baik secara langsung maupun tidak langsung melalui kepuasan kerja.

Berdasarkan hasil tersebut, saran manajerial adalah menerapkan gaya kepemimpinan nurturant dan gaya berorientasi tugas. Lebih dari itu adalah menciptakan dan menjaga keterlibatan mandor perkebunan dalam budaya organisasi, sejalan dengan pemberian tingkat kepuasan kerja yang dirasakan oleh mandor perkebunan yang pada akhirnya akan meningkatkan kinerja mandor perkebunan yang diharapkan dapat mencapai produksi tebu per hektar. sesuai dengan potensi varietas yang ada.
\end{abstract}

\title{
INTRODUCTION
}

Terjadinya pergantian direksi di tahun 2011 menginisiasi perombakan susunan sumber daya manusia di level pejabat menengah sampai puncak. PG Semboro dihuni pemimpin-pemimpin berusia relatif muda termasuk di bagian tanaman. Adanya pemimpin baru dengan usia muda khususnya di bagian tanaman memberi warna gaya kepemimpinan yang berbeda dari yang sudah ada.

Budaya organisasi merupakan bagian dari lingkungan internal yang tidak terpisahkan dari organisasi. Banyak pakar menyebutkan bahwa budaya organisasi dapat menjadi basis adaptasi dan kunci keberhasilan organisasi sehingga banyak penelitian dilakukan untuk mengidentifikasi nilai-nilai atau norma-norma perilaku yang bisa 
memberikan kontribusi besar bagi keberhasilan organisasi (Abdul Rashid et.al, 2003 dalam Mariam, 2009). Jajaran direksi juga mencoba menysusun dan mengenalkan kembali di awal jabatannya seperti visi dan misi, nilai-nilai budaya perusahaan yang dikenal dengan slogan ProAKSI (Produktif, Amanah, Kualitas, Simpatik dan Inovatif).

Dalam kurun dua tahun terakhir kinerja bagian tanaman di PG Semboro menunjukkan hal yang positif. Hal ini dapat dilihat dari jumlah tebu yang digiling dan rendemen yang menunjukkan angka paling tinggi sejak sistem remelt carbonatase digunakan pada tahun 2009. Artinya terdapat penambahan luas areal sewa dan tebu rakyat diikuti dengan penebangan yang lebih MBS (Manis, Bersih, Segar) disamping didukung dengan iklim yang menunjang. Namun peningkatan angka tebu yang digiling dan rendemen tersebut tidak diikuti dengan pencapaian produksi tebu per hektar yang belum bisa menembus potensi varietas yang mestinya bisa diraih yaitu \pm 100 ton/Ha dan justru mengalami penurunan di tahun 2013 lalu.

Semua karyawan yang bekerja pada suatu organisasi atau perusahaan tentu sangat menginginkan kepuasan kerja yang maksimal. Untuk mencapai tingkat kepuasan tersebut, kinerja karyawan dapat dipengaruhi beberapa faktor diantaranya adalah gaya kepemimpinan dan budaya organisasi ditempat kerja. Hal tersebut sejalan dengan hasil penelitian Mariam (2009) yaitu gaya kepemimpinan dan budaya organisasi mempengaruhi secara positif kinerja melalui kepuasan kerja karyawan. Seorang mandor kebun tentu mempersepsikan gaya kepemimpinan atasannya dan juga budaya organisasi sedemikian rupa sehingga memberi kontribusi pada kepuasan kerja dan pada akhirnya membentuk pola sikap dalam pekerjaan.

\section{LITERATURE REVIEW}

Menurut Yukl (2005), kepemimpinan adalah proses untuk mempengaruhi orang lain, untuk memahami dan setuju dengan apa yang perlu dilakukan dan bagaimana tugas itu dilakukan secara efektif, serta proses untuk memfasilitasi upaya individu dan kolektif untuk mencapai tujuan bersama. Faktor kepemimpinan mempunyai keterkaitan erat terhadap kinerja yang dicapai oleh karyawan. Sebab di dalam organisasi apapun bentuknya baik besar maupun kecil pasti memerlukan seorang pemimpin. Oleh karena itu pemimpin yang baik dapat menjadi panutan atau teladan bagi bawahan dalam bekerja dan sekaligus dapat memberikan motivasi dan semangat kerja di dalam organisasi (Porwani, Sri dan Zunaidah, 2009).

Fuad (2004) dalam Mariam (2009) menyatakan budaya organisasi menjadi identitas atau karakter utama organisasi yang dipelihara dan dipertahankan. Suatu budaya yang kuat merupakan perangkat yang sangat bermanfaat untuk mengarahkan perilaku, karena membantu karyawan untuk melakukan pekerjaan yang lebih baik 
sehingga setiap karyawan pada awal karirnya perlu memahami budaya dan bagaimana budaya tersebut terimplementasikan.

Budaya organisasi dapat mempengaruhi bagaimana orang menetapkan tujuan pribadi dan profesional, melakukan tugas-tugas dan mengelola sumber daya untuk mencapai tujuan. Budaya organisasi mempengaruhi cara berpikir orang secara sadar, mengambil keputusan dan melihat, merasa dan bertindak (Hansen dan Wernerfelt, 1989; Schein, 1990 dalam Lok, 2003).

Definisi kepuasan kerja dikemukakan oleh Luthans (1998) adalah suatu keadaan emosi seseorang yang positif maupun menyenangkan yang dihasilkan dari penilaian suatu pekerjaan atau pengalaman kerja. Lima model kepuasan kerja, yang dikemukakan oleh Kreitner \& Kinichi (2005) adalah ; Pertama pemenuhan kebutuhan, model ini menjelaskan bahwa kepuasan ditentukan oleh karakteristik dari sebuah pekerjaan yang memungkinkan seseorang dapat memenuhi kebutuhannya. Kedua ketidakcocokan, model ini menjelaskan bahwa kepuasan adalah hasil dari harapan yang terpenuhi. Ketiga pencapaian nilai, model ini menjelaskan bahwa kepuasan berasal dari persepsi bahwa suatu pekerjaan memungkinkan untuk pemenuhan nilai-nilai kerja yang penting dari individu. Keempat persamaan, model ini kepuasan adalah suatu fungsi dari bagaimana seorang individu diperlakukan ditempat kerja. Kelima watak/genetik, model ini berusaha menjelaskan beberapa orang merasa puas dengan situasi dan kondisi kerja tertentu, namun sebagian lagi merasa tidak puas dengan kondisi tersebut.

Pembahasan tentang kepuasan kerja karyawan tidak bisa dilepaskan dari kenyataan bahwa kepuasan kerja karyawan dapat dicapai apabila semua harapannya dapat dipenuhi dalam melaksanakan tugas pekerjaannya. Kepuasan kerja merupakan refleksi dari perasaan dan sikap individu terhadap pekerjaannya, yang merupakan interaksi antara yang bersangkutan dengan lingkungan kerjanya.

Keberhasilan suatu organisasi dipengaruhi oleh kinerja (job performance) karyawan, untuk itu setiap perusahaan akan berusaha untuk meningkatkan kinerja karyawannya dalam mencapai tujuan organisasi yang telah ditetapkan. Budaya organisasi yang tumbuh dan terpelihara dengan baik akan mampu memacu organisasi ke arah perkembangan yang lebih baik. Di sisi lain, kemampuan pemimpin dalam menggerakkan dan memberdayakan karyawan akan mempengaruhi kinerja.

Soeprihantono (1988) mengatakan bahwa kinerja merupakan hasil pekerjaan seorang karyawan selama periode tertentu dibandingkan dengan berbagai kemungkinan, misalnya standard, target/sasaran/kriteria yang telah ditentukan terlebih dahulu dan telah disepakati bersama. Kinerja merupakan hasil atau tingkatan keberhasilan seseorang secara keseluruhan selama periode tertentu dalam melaksanakan tugas dibandingkan dengan standar hasil kerja, target atau sasaran atau kriteria yang telah ditentukan terlebih dahulu dan telah disepakati bersama (Rivai, 2004). Lebih lanjut Rivai 
menyatakan bahwa kinerja tidak berdiri sendiri tapi berhubungan dengan kepuasan kerja dan kompensasi, dipengaruhi oleh ketrampilan, kemampuan dan sifat - sifat individu. Dengan kata lain kinerja ditentukan oleh kemampuan, keinginan dan lingkungan. Oleh karena itu agar mempunyai kinerja yang baik, seseorang harus mempunyai keinginan yang tinggi untuk mengerjakan dan mengetahui pekerjaannya serta dapat ditingkatkan apabila ada kesesuaian antara pekerjaan dan kemampuan.

McNeese (1993) menyimpulkan bahwa faktor-faktor kinerja yang paling sering digunakan sebagai indikator penelitian adalah pengetahuan, kemampuan, keterampilan kerja, sikap terhadap pekerjaan (antusiasme, komitmen, dan motivasi), kualitas kerja, volume hasil produksi dan interaksi (komunikasi, hubungan dalam kelompok), pembuatan perencanaan, pengendalian biaya serta pemahaman data.

Berdasarkan uraian tersebut maka kerangka pemikiran teoritis dalam penelitian ini dapat digambarkan sebagai berikut :

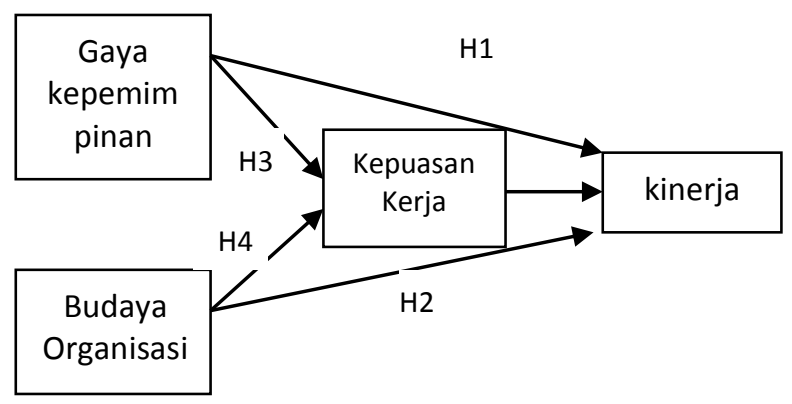

H1 : Gaya Kepemimpinan berpengaruh terhadap kinerja.

H2 : Budaya Organisasi berpengaruh terhadap kinerja.

H3 : Gaya Kepemimpinan melalui kepuasan kerja berpengaruh terhadap kinerja.

H4 : Budaya organisasi melalui kepuasan kerja berpengaruh terhadap kinerja.

\section{RESEARCH METHODS}

Metode yang digunakan dalam penelitian ini adalah Metode kuantitatif. Teknik analisis data yang digunakan dalam penelitian ini menggunakan partial least square dikarenakan peneliti ingin memprediksi hubungan antar variabel yang didapat dari hasil survey langsung dan survey literatur. Pengujian dalam penelitian ini menggunakan software SmartPLS versi 2.0.

Populasi dalam penelitian ini adalah mandor kebun yang berhubungan langsung dalam ketersediaan bahan baku tebu di wilayah PG Semboro. Populasi terdiri dari 35 orang berstatus dinas. Sumber data yang digunakan dalam penelitian ini adalah berasal dari data primer dan sekunder. Untuk mendapatkan data primer digunakan alat 
pengumpul data dengan menggunakan kuisoner sebagai alat pengumpul data. Penelitian ini menggunakan 4 (empat) variabel yang akan diuji hubungannya secara langsung. Skor dari keempat variabel ini diperoleh dari skor total pengukuran masingmasing indikator dari 4 (empat) variabel.

\section{RESULT AND ANALYSIS}

\section{Deskripsi variabel gaya kepemimpinan}

Variabel gaya kepemimpinan terdiri atas empat indikator yaitu gaya partisipatif, gaya pengasuh, gaya otoriter, gaya berorientasi tugas. Berikut ini adalah deskripsi jawaban masing-masing pertanyaan pada variabel gaya kepemimpinan:

Tabel 1

Deskripsi Jawaban Variabel gaya kepemimpinan

\begin{tabular}{|c|c|c|c|c|c|c|c|}
\hline Indikator & STS & TS & $\mathbf{R}$ & $\mathbf{S}$ & SS & Mean & Kategori \\
\hline GK1 & & 3 & 6 & 20 & 6 & 3.828 & Tinggi \\
\hline GK2 & & 2 & 2 & 28 & 3 & 3.914 & Tinggi \\
\hline GK3 & & 7 & 23 & & 5 & 3.743 & Tinggi \\
\hline GK4 & & 6 & 1 & 18 & 10 & 3.914 & Tinggi \\
\hline \multicolumn{6}{|c|}{ Gaya Kepemimpinan (GK) } & 3.850 & Tinggi \\
\hline
\end{tabular}

Sumber : Data primer diolah, 2014

\section{Deskripsi variabel budaya organisasi}

Variabel budaya organisasi terdiri atas empat indikator yaitu komunikasi, keteraturan, tim kerja, kreativitas. Berikut ini adalah deskripsi jawaban masing-masing pertanyaan pada variabel budaya organisasi:

Tabel 2

Deskripsi Jawaban Variabel budaya organisasi

\begin{tabular}{c|c|c|c|c|c|c|c}
\hline \multirow{2}{*}{ Indikator } & STS & TS & R & S & SS & Mean & Kategori \\
\hline BO1 & & 5 & 1 & 23 & 6 & 3.857 & Tinggi \\
BO2 & & 8 & 5 & 20 & 2 & 3.457 & Tinggi \\
BO3 & & 5 & 2 & 27 & 1 & 3.686 & Tinggi \\
BO4 & 7 & 4 & 16 & 7 & 3.600 & Tinggi \\
\hline
\end{tabular}

Sumber : Data primer diolah, 2014

\section{Deskripsi variabel kepuasan kerja}


Variabel kepuasan kerja terdiri atas tiga indikator yaitu kepuasan kerja terhadap kompensasi yang diterima karyawan, kepuasan terhadap rekan kerja, kepuasan terhadap supervisor. Berikut ini adalah deskripsi jawaban masing-masing pertanyaan pada variable kepuasan kerja:

Tabel 3

Deskripsi Jawaban Variabel kepuasan kerja

\begin{tabular}{|c|c|c|c|c|c|c|c|}
\hline Indikator & STS & TS & $\mathbf{R}$ & $\mathbf{S}$ & SS & Mean & Kategori \\
\hline KK1 & & 4 & 1 & 19 & 11 & 4.057 & Tinggi \\
\hline KK3 & & 4 & 2 & 22 & 7 & 3.914 & Tinggi \\
\hline KK5 & & 4 & 2 & 28 & 1 & 3.743 & Tinggi \\
\hline \multicolumn{6}{|c|}{ Kepuasan Kerja (KK) } & 3.905 & Tinggi \\
\hline
\end{tabular}

Sumber : Data primer diolah, 2014

\section{Deskripsi jawaban variabel kinerja}

Variabel kinerja terdiri atas enam indikator yaitu kualitas, penyelesaian tugas tepat waktu, bekerja tanpa pengawasan, perencanaan kerja, pengendalian biaya, memahami data - data dan informasi. Berikut ini adalah deskripsi jawaban masing-masing pertanyaan pada variabel kinerja:

Tabel 4

Deskripsi Jawaban Variabel kinerja

\begin{tabular}{cccccccc}
\hline Indikator & STS & TS & R & S & SS & Mean & Kategori \\
\hline K1 & 4 & 1 & 18 & 12 & 4.086 & Tinggi \\
K2 & 7 & 2 & 22 & 4 & 3.657 & Tinggi \\
K3 & 4 & 5 & 16 & 10 & 3.914 & Tinggi \\
K4 & 6 & & 28 & 1 & 3.686 & Tinggi \\
K5 & & 3 & 26 & 6 & 4.086 & Tinggi \\
K6 & 5 & 3 & 23 & 4 & 3.743 & Tinggi \\
\hline
\end{tabular}

Sumber : Data primer diolah, 2014

\section{Evaluasi Inner Model}

Tabel 5

Hasil R-Square

\begin{tabular}{|c|c|}
\hline Variabel & R Square \\
\hline \multicolumn{2}{|l|}{ Gaya Kepemimpinan } \\
\hline \multicolumn{2}{|l|}{ Budaya Organisasi } \\
\hline Kepuasan Kerja & 0,632 \\
\hline Kinerja & 0,926 \\
\hline
\end{tabular}

Sumber: Data Primer Diolah, 2014 
Berdasarkan tabel 5. diketahui bahwa nilai $\mathrm{R}^{2}$ untuk variabel kepuasan kerja adalah sebesar 0,632. Nilai ini menunjukan bahwa kepuasan kerja dipengaruhi oleh gaya kepemimpinan dan budaya organisasi sebesar $63,2 \%$, sisanya sebesar $36,8 \%$ dipengaruhi oleh faktor lain yang tidak terdapat dalam model.

Penilaian Goodness of fit pada model PLS dapat diketahui dari nilai $Q^{2}$. Nilai $Q^{2}$ memiliki arti yang sama dengan koefisien determinasi (R-square/ $R^{2}$ ) dalam analisis regresi. Semakin tinggi $Q^{2}$, maka model dapat dikatakan semakin fit dengan data. Dari tabel diatas, dapat diketahui nilai $\mathrm{Q}^{2}$ adalah sebagai berikut:

Nilai $Q^{2}=1-((1-0,926) \times(1-0,632))$

$$
=0,973=97,3 \%
$$

Pada model dalam penelitian ini nilai dari Q-square total yang dihasilkan adalah sebesar $97,3 \%$, yang berarti besarnya presentase data yang dapat dijelaskan oleh model adalah sebesar 97,3 \% sedangkan sisanya 2,7 \% merupakan pengaruh dari variabel lain yang tidak terdapat dalam model.

Tabel 6

Hasil Inner Weight

\begin{tabular}{lrrrr}
\hline & & \multicolumn{3}{c}{ Standard } \\
& Original Sample (O) & Sample Mean (M) & Deviation (STDEV) & T Statistics (|O/STERR|) \\
\hline GK -> K & 0,582 & 0,566 & 0,083 & 7,054 \\
GK -> KK & 0,366 & 0,378 & 0,105 & 3,490 \\
BO -> K & 0,355 & 0,340 & 0,062 & 5,751 \\
BO -> KK & 0,579 & 0,568 & 0,097 & 5,983 \\
KK -> K & 0,215 & 0,227 & 0,083 & 2,586 \\
\hline
\end{tabular}

Sumber: Data Primer Diolah, 2014

Berdasarkan tabel 6 maka dapat terlihat hubungan antar variabel sebagai berikut:

a. Pengaruh gaya kepemimpinan terhadap kinerja. Koefisien parameter yang dapat dilihat dari nilai Original Sample Estimate dari pengaruh gaya kepemimpinan terhadap kinerja sebesar 0,582. Dengan nilai T-statistik sebesar 7,054 yang lebih besar dari 1,96. Hal ini berarti, terdapat pengaruh positif dan signifikan dari pengaruh gaya kepemimpinan terhadap kinerja. Pengaruh positif yang dihasilkan memiliki arti semakin tinggi peran pengaruh gaya kepemimpinan terhadap kinerja.

b. Pengaruh gaya kepemimpinan terhadap kepuasan kerja. Koefisien parameter yang dapat dilihat dari nilai Original Sample Estimate dari pengaruh gaya kepemimpinan terhadap kinerja sebesar 0,366. Dengan nilai T-statistik sebesar 3,490 yang lebih besar dari 1,96. Hal ini berarti, terdapat pengaruh positif dan signifikan dari pengaruh gaya kepemimpinan terhadap kepuasan kerja. Pengaruh positif yang dihasilkan memiliki arti semakin tinggi peran pengaruh gaya kepemimpinan terhadap kepuasan kerja.

c. Pengaruh Budaya organisasi terhadap kinerja. Koefisien parameter yang dapat dilihat dari nilai Original Sample Estimate dari pengaruh Pengaruh Budaya organisasi dengan 
kinerja sebesar 0,355. Dengan nilai T-statistik sebesar 5,751 yang lebih besar dari 1,96. Hal ini berarti, terdapat pengaruh positif dan signifikan dari pengaruh budaya organisasi dengan kinerja. Pengaruh positif yang dihasilkan memiliki arti semakin tinggi peran pengaruh budaya organisasi terhadap kinerja.

d. Pengaruh budaya organisasi terhadap kepuasan kerja. Koefisien parameter yang dapat dilihat dari nilai Original Sample Estimate dari pengaruh Pengaruh Budaya organisasi dengan kepuasan kerja sebesar 0,579. Dengan nilai T-statistik sebesar 5,983 yang lebih besar dari 1,96. Hal ini berarti, terdapat pengaruh positif dan signifikan dari pengaruh budaya organisasi dengan kepuasan kerja. Pengaruh positif yang dihasilkan memiliki arti semakin tinggi peran pengaruh budaya organisasi terhadap kepuasan kerja.

e. Pengaruh kepuasan kerja terhadap Kinerja. Koefisien parameter yang dapat dilihat dari nilai Original Sample Estimate dari pengaruh kepuasan kerja dengan kinerja sebesar 0,215. Dengan nilai T-statistik sebesar 2,586 yang lebih besar dari 1,96. Hal ini berarti, terdapat pengaruh positif dan signifikan dari kepuasan kerja terhadap kinerja. Pengaruh positif yang dihasilkan memiliki arti semakin tinggi peran kepuasan kerja maka kinerja akan semakin tinggi.

\section{Uji hipotesis 1}

Hipotesis 1 pada penelitian ini adalah gaya kepemimpinan berpengaruh positif terhadap kinerja. Berdasarkan hasil analisis, besarnya nilai t-statistik adalah 7,054 dan signifikan pada $\alpha=0,05$. Dapat disimpulkan bahwa hipotesis $\mathrm{H} 1$ diterima karena nilai tstatistik tersebut berada di atas nilai kritis \pm 1 .96. Sehingga dapat dijelaskan bahwa terdapat pengaruh yang signifikan antara variabel gaya kepemimpinan terhadap kinerja.

\section{Uji hipotesis 2}

Hipotesis 2 pada penelitian ini adalah budaya organisasi berpengaruh positif terhadap kinerja. Berdasarkan hasil analisis, besarnya nilai t-statistik adalah 5,751 dan signifikan pada $\alpha=0,05$. Dapat disimpulkan bahwa hipotesis $\mathrm{H} 2$ diterima karena nilai $\mathrm{t}$ statistik tersebut berada di atas nilai kritis \pm 1.96 . Sehingga dapat dijelaskan bahwa terdapat pengaruh yang signifikan antara variabel budaya organisasi terhadap kinerja.

\section{Uji hipotesis 3}

Untuk menjawab hipotesis 3 dalam penelitian ini yang menyatakan bahwa gaya kepemimpinan berpengaruh signifikan terhadap kinerja melalui kepuasan kerja sebagai variabel intervening, dapat dilakukan dengan menghitung nilai path coefficient (koefisien jalur) pengaruh langsung dan pengaruh tidak langsung. Apabila nilai path coefficient pengaruh tidak langsung lebih besar dari nilai path coefficient pengaruh langsungnya maka dapat dikatakan ada variabel intervening (Kusumawati, 2008). Hasil pengujian pengaruh langsung dan tidak langsung dapat dilihat pada tabel di bawah ini. 
Tabel 7

Pengaruh Langsung dan Tidak Langsung Variabel

\begin{tabular}{|c|c|c|c|c|c|c|c|}
\hline \multirow[t]{2}{*}{ 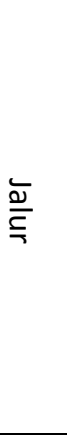 } & \multirow[t]{2}{*}{ 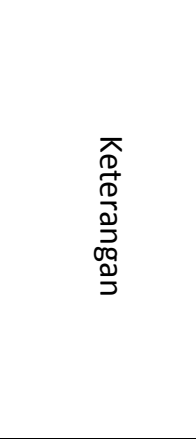 } & 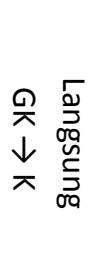 & 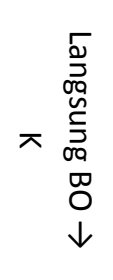 & 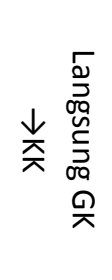 & 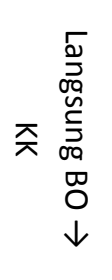 & 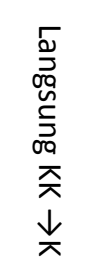 & 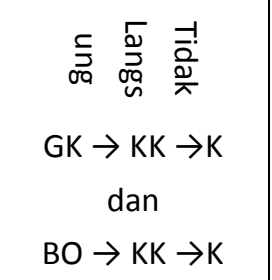 \\
\hline & & A & $B$ & $C$ & $\mathrm{D}$ & $E$ & $\begin{array}{c}F \\
F 1=(A)+(C X E) \\
F 1=(B)+(D X E)\end{array}$ \\
\hline 1 & $\mathrm{GK} \rightarrow \mathrm{KK} \rightarrow \mathrm{K}$ & 0,582 & & 0,366 & & 0,215 & 0,661 \\
\hline 2 & $\mathrm{BO} \rightarrow \mathrm{KK} \rightarrow \mathrm{K}$ & & 0,355 & & 0,579 & 0,215 & 0,479 \\
\hline
\end{tabular}

Dari tabel di atas, dapat dilihat bahwa nilai koefisien jalur pengaruh langsung gaya kepemimpinan terhadap kinerja adalah sebesar 0,582 sedangkan koefisien jalur pengaruh tidak langsung gaya kepemimpinan terhadap kinerja melalui kepuasan kerja adalah 0,661 . Hasil perhitungan tersebut menunjukkan bahwa koefisien pengaruh tidak langsung lebih besar dari pengaruh langsungnya maka dapat dikatakan hubungan gaya kepemimpinan terhadap kinerja dimediasi variabel kepuasan kerja sebagai variabel intervening. Dapat disimpulkan bahwa hipotesis H3 diterima. Sehingga dapat dijelaskan bahwa terdapat pengaruh yang signifikan antara variabel gaya kepemimpinan terhadap kinerja melalui kepuasan kerja.

\section{Uji hipotesis 4}

Untuk menjawab hipotesis 4 dalam penelitian ini yang menyatakan bahwa budaya organisasi berpengaruh signifikan terhadap kinerja melalui kepuasan kerja sebagai variabel intervening, dapat dilakukan dengan menghitung nilai path coefficient (koefisien jalur) pengaruh langsung dan pengaruh tidak langsung. Apabila nilai path coefficient pengaruh tidak langsung lebih besar dari nilai path coefficient pengaruh langsungnya maka dapat dikatakan ada variabel intervening (Kusumawati, 2008).

Dari tabel 5.19 dapat dilihat bahwa nilai koefisien jalur pengaruh langsung budaya organisasi terhadap kinerja adalah sebesar 0,355, sedangkan koefisien jalur pengaruh tidak langsung budaya organisasi terhadap kinerja melalui kepuasan kerja adalah sebesar 0,479. Hasil perhitungan tersebut menunjukkan bahwa koefisien pengaruh tidak langsung lebih besar dari pengaruh langsungnya maka dapat dikatakan hubungan budaya organisasi terhadap kinerja dimediasi variabel kepuasan kerja sebagai variabel intervening. Dapat disimpulkan bahwa hipotesis H4 diterima. Sehingga dapat dijelaskan bahwa terdapat pengaruh yang signifikan antara variabel budaya organisasi terhadap kinerja melalui kepuasan kerja.

\section{Pembahasan Hasil Penelitian}


Penelitian ini menguji apakah terdapat pengaruh langsung gaya kepemimpinan dan budaya organisasi terhadap kinerja. Penelitian ini juga menguji apakah terdapat pengaruh tidak langsung gaya kepemimpinan dan budaya organisasi terhadap kinerja melalui mediasi kepuasan kerja karyawan sebagai variabel intervening.

Penerimaan hipotesis 1 mengindikasikan bahwa gaya kepemimpinan seorang KKW mempengaruhi kinerja seorang mandor kebun dan signifikan, yang berarti dalam penelitian ini menunjukkan bahwa semakin tinggi persepsi penilaian gaya kepemimpinan KKW oleh seorang mandor kebun cenderung akan meningkatkan kinerjanya. Hal ini sejalan dengan penelitian sebelumnya, yakni penelitian Shea (1999) yang mengatakan bahwa gaya kepemimpinan berpengaruh positif terhadap peningkatan kinerja.

Artinya, ketika seorang mandor kebun menerima gaya kepemimpinan KKW-nya maka mereka dapat bekerja dengan baik. Tekanan terhadap mandor kebun baik berupa kualitas pekerjaan, biaya maupun produksi apabila mampu diterjemahkan dan disampaikan dengan baik oleh seorang KKW dengan bahasa kepemimpinan yang dapat diterima oleh mandor kebun akan mmbuat situasi kerja mandor kebun seperti tidak dalam tekanan sehingga mereka dapat bekerja dengan optimal dengan mengeluarkan segala daya kemampuannya untuk pekerjaannya.

Penerimaan hipotesis 2 mengindikasikan bahwa budaya organisasi yang ada mempengaruhi kinerja seorang mandor kebun dan signifikan, yang berarti dalam penelitian ini menunjukkan bahwa semakin tinggi persepsi terhadap budaya organisasi oleh seorang mandor kebun cenderung akan meningkatkan kinerjanya. Hal ini sejalan dengan penelitian Mariam (2009) bahwa ada pengaruh yang searah antara budaya organisasi dengan kinerja karyawan.

Komunikasi yang intensif antara KKW dan mandor kebun, adanya tim kerja yang kompak membuat perintah dan arahan KKW diterima dan dilaksanakan dengan baik dan benar oleh mandor kebun. Adanya keteraturan dan ide-ide baru dari mandor kebun memberi warna tersendiri terhadap perintah dan arahan sehingga output pekerjaan kebun menjadi semakin baik.

Penerimaan hipotesis 3 mengindikasikan bahwa gaya kepemimpinan seorang KKW melalui kepuasan kerja mempengaruhi kinerja seorang mandor kebun dan signifikan, yang berarti dalam penelitian ini menunjukkan bahwa semakin tinggi persepsi penilaian gaya kepemimpinan oleh seorang mandor kebun akan meningkatkan kepuasan kerja dan cenderung akan meningkatkan kinerjanya. Hal ini sesuai dengan hasil penelitian Sudarmadi (2007) bahwa gaya kepemimpinan seorang melalui kepuasan kerja mempengaruhi kinerja.

Persepsi yang tinggi mandor kebun terhadap gaya kepemimpinan partisipatif, gaya pengasuh, gaya otoriter dan gaya berorientasi pada tugas yang ada di PG Semboro, 
difasilitasi oleh kepuasan mandor kebun itu sendiri atas kompensasi yang diterima, hubungan dengan rekan kerja dan supervisi KKW-nya dapat mempengaruhi kinerja mandor kebun itu sendiri secara positif.

Penerimaan hipotesis 4 mengindikasikan bahwa budaya organisasi yang ada, melalui kepuasan kerja mempengaruhi kinerja seorang mandor kebun dan signifikan, yang berarti dalam penelitian ini menunjukkan bahwa semakin tinggi persepsi terhadap budaya organisasi oleh seorang mandor kebun akan meningkatkan kepuasan kerja dan cenderung akan meningkatkan kinerjanya. Hal ini sesuai dengan hasil penelitian Sudarmadi (2007) bahwa budaya organisasi melalui kepuasan kerja mempengaruhi kinerja.

Persepsi yang tinggi mandor kebun terhadap komunikasi dengan rekan, keteraturan organisasi, tim kerja dan adanya kreativitas yang ada di PG Semboro, difasilitasi oleh kepuasan mandor kebun itu sendiri atas kompensasi yang diterima, hubungan dengan rekan kerja dan supervisi KKW-nya dapat mempengaruhi kinerja mandor kebun itu sendiri secara positif dan signifikan.

\section{CONCLUSION}

Penelitian ini berusaha menguji pengaruh gaya kepemimpinan dan budaya organisasi terhadap kinerja mandor kebun PG Semboro PTPN XI (persero) dengan kepuasan kerja sebagai variabel intervening dari pengembangan literatur sebelumnya. Dari hasil pengujian partial least square dengan menggunakan bantuan software statistik SmartPLS, disimpulkan bahwa Gaya Kepemimpinan (GK) berpengaruh positif terhadap kinerja. Penerimaan hipotesis 1 mengindikasikan bahwa gaya kepemimpinan seorang KKW mempengaruhi kinerja seorang mandor kebun dan signifikan. Budaya Organisasi (BO) berpengaruh positif terhadap kinerja. Penerimaan hipotesis 2 mengindikasikan bahwa budaya organisasi yang ada mempengaruhi kinerja seorang mandor kebun dan signifikan. Gaya Kepemimpinan (GK) berpengaruh positif terhadap kinerja melalui kepuasan kerja karyawan. Penerimaan hipotesis 3 mengindikasikan bahwa gaya kepemimpinan seorang KKW melalui kepuasan kerja mempengaruhi kinerja seorang mandor kebun dan signifikan Budaya Organisasi (BO) berpengaruh positif terhadap kinerja melalui kepuasan kerja karyawan. Penerimaan hipotesis 4 mengindikasikan bahwa budaya organisasi yang ada, melalui kepuasan kerja mempengaruhi kinerja seorang mandor kebun dan signifikan Hasil uji pengaruh langsung dan tidak langsung terbukti bahwa konstruk kepuasan kerja (KK) memediasi hubungan antara gaya kepemimpinan (GK) terhadap kinerja (K) dan memediasi hubungan antara budaya organisasi (BO) terhadap kinerja (K). Hal ini sesuai dengan hasil penelitian Sudarmadi (2007) bahwa bahwa gaya kepemimpinan, budaya organisasi melalui kepuasan kerja mempengaruhi kinerja.

Kinerja mandor kebun dipengaruhi oleh banyak faktor diantaranya gaya kepemimpinan dan budaya organisasi baik secara langsung maupun tidak langsung melalui kepuasan kerja. Pengelolaan sumber daya manusia di level ini dirasa penting mengingat mandor kebun adalah 
ujung tombak di lapangan bagian on farm sebuah pabrik gula. Kebijakan yang tepat akan meningkatkan kinerja mandor kebun dengan harapan untuk meningkatkan produktifitas tebu per hektar. Hal tersebut dapat disusun dengan memperhatikan hasil penelitian ini yaitu dengan mengoptimalkan nilai-nilai atau indikator yang dapat meningkatkan kinerja mandor kebun.

Kebijakan yang dapat diambil diantaranya memberikan in house training kepada KKW akan pentingnya mengembangkan gaya kepemimpinan pengasuh dan gaya kepemimpinan berorientasi tugas serta meningkatkan komunikasi kepada mandor kebun yang menjadi nilai kunci untuk meningkatkan kinerja mandor kebun di PG Semboro. Dalam hal recruitment dapat mempetimbangkan untuk merekrut sumber daya manusia yang tidak hanya cakap dalam hal teknis tetapi juga cakap dalam hal berkomunikasi dengan rekan kerja dan lingkungannya.

\section{REFERENCES}

Anthony, R. 1992. Rahasia Membangun Kepercayaan Diri. (terjemahan Rita Wiryadi). Jakarta: Binarupa Aksara

Arikunto, S. 2002. Prosedur Suatu Penelitian: Pendekatan Praktek. Edisi Revisi Kelima. Penerbit Rineka Cipta. Jakarta.

Celluci, Anthony J. \& David L. De Vries, 1978, Measuring Managerial Satisfaction: A Manual for The M.J. SQ Technical Report II, Center for Creative Leadership.

Currivan D. B., 1999, "The Causal Order of Job Satisfaction and Organizational Commitment in Models of Employee Turnover", Human Resource Management Review, Vol.9.

Fuad, Mas'ud, 2004, Survai Diagnosis Organisasional : Konsep dan Aplikasi, Badan Penerbit UNDIP, Semarang.

Ghozali, I., 2006. Structural Equation Modeling: Metode Alternatif Dengan Partial Least Square (PLS), Semarang: Universitas Diponegoro.

Harris S. G. \& Mossholder K. W, 1996, "The Effective Implication of Perceived Congruence with Cultural Dimensions During Organizational Transformation", Journal of Management, 22, 527-547.

laffaldano M. T., \& Muechinsky, 1985, “Job Satisfaction and Job Performance: a Metaanalysis", Psychologycal Bulletin, 97, 251-273.

Ivancevich, J.M., Konopaske, R., dan Matteson M.T. 2006. Perilaku dan Manajemen Organisasi. Jilid 1 dan 2. Edisi ketujuh. Erlangga, Jakarta.

Jogiyanto, 2009. Teori Portofolio dan analisis investasi. Penerbit :BPFE Yogyakarta.

Ken W. Parry, Sarah B. Proctor-Thomson. 2003. Leadership, culture and performance: The case of the New Zealand public sector.

Kuhlmann. 2010. Culture-Driven Leadership. http://iveybusinessjournal.com/ topics/ leadership/culture-driven-leadership\#. Uk9gAFJNjMA

Kusumawati, Ratna. 2008. Analisis pengaruh budaya organisasi Dan gaya kepemimpinan terhadap Kepuasan kerja untuk meningkatkan Kinerja karyawan (studi kasus pada rs roemani semarang). Universitas Diponegoro semarang. 
Lawler E.E. \& Porter L.W., 1969, "The Effect of Performance on Job Satisfaction", Industrial Relations, Vol.8, p.20-8.

Locke E. A., 1970, "Job Satisfaction and Job Performance: a Theorytical Analysis", Organization Behavior and Human Performance, Vol.5, p.484-500.

Lok, Peter. 2003. The effect of organisational culture and leadership style on job satisfaction and organisational commitment A cross-national comparison. UNSW, New South Wales, Australia.

Lund, Daulatram B. 2003. "Organizational Culture and Job Satisfaction",Journal of Business \& Industrial Marketing, Vol. 18, No.3, pp.219-236

Luthans F., 1992, Organizational Behavioural, 7th Edition, McGraw-Hill, New York. ., 1998. Organizational Behavior, Seventh Edition, International Edition, New York: McGraw-Hill Companies, Inc.

Mariam, Rani. 2009. Pengaruh Gaya Kepemimpinan Dan Budaya Organisasi Terhadap Kinerja Karyawan Melalui Kepuasan Kerja Karyawan Sebagai Variabel Intervening Studi Pada Kantor Pusat PT.Asuransi Jasa Indonesia (Persero). Universitas Diponegoro.

Mathis, Robert L. dan John H. Jackson. 2002. Manajemen Sumber Daya Manusia, Edisi Pertama Salemba Empat, Jakarta

McNeese-Smith, Donna, 1993, Increasing Employee Productivity, Job Satisfaction and Organizational Commitment, Hospital \&Health Service Administration, Vol.41:2, Summer, 160-175

Muhadi. 2007. Analisis Pengaruh Kepuasan Kerja Terhadap Komitmen Organisasional dalam Mempengaruhi Kinerja Karyawan (Studi pada Karyawan Administrasi Universitas Diponegoro). Thesis, Universitas Diponegoro.

Mulhern, Frank. 2009. Leadership and the Performance of People in Organizations: Enriching Employees and Connecting People. Northwestern University

Nasir, M. 1988. Metode Penelitian. Ghalia Indonesia, Jakarta,. Indonesia.

Ogbonna dan Harris. 2000. Leadership style, organizational culture and performance: empirical evidence from UK companies. Int. J. of Human Resource Management 11:4 August $2000766-788$

Ostroff, Cheri, 1992, "The Relationship Between Satisfaction, Attitude and Performance : An Organizational Level Analysis", Journal of Appplied Psychology, Vol 77, No. 5.

Petty M. M, G. W. McGee, \& J. W. Cavender, 1984, “A Meta-Analysis of The Relationship between Individual Performance", Academy of Management Review 9(4): 712-21.

Pool, S.W. 2000, Organizational culture and its relationship between job tension in measuring outcomes among business executives Journal of Management Development, Vol. 19, No. 1, pp. 32-49

Porwani, Sri dan Zunaidah. 2009. Pengaruh Budaya Organisasi dan Gaya Kepemimpinan Transformasional Terhadap Kinerja Karyawan PT. Tambang Batubara Bukit Asam (Persero) Tanjung Enim. Jurusan Administrasi Niaga Politeknik Negeri Sriwijaya, Palembang.

Pradeep, Durga Devi dan N.R.V Prabhu.2011. The Relationship between Effective Leadership and Employee Performance. International Conference on Advancements in Information Technology. IACSIT Press, Singapore. 
Recardo, Renald and Jolly, Jennifer. 1997. Organizational Cultural Team, SAM Advanced Management Journal.

Rivai, Veithzal. (2004). Kepemimpinan dan Perilaku Organisasi.Edisi Kedua. Jakarta: PT. Raja Grafindo Persada.

Robbins, Stephen. P. 2006. Perilaku Organisasi (alih bahasa Drs. Benjamin Molan), Edisi Bahasa Indonesia, Klaten: PT INT AN SEJATI.

Robbins, S., dan Timothy A. J., 2008, "Perilaku Organisasi, Organizational Behaviour", Buku Terjemahan, Jakarta : Gramedia.

Rochmawati, Lusa. 2009. Faktor yang mempengaruhi komunikasi.

Schein E., 1985, Organizational Culture and Leadership, San Frasisco Jossey - Bass.

Shea, Christine M, 199, "The Effect of Leadership Style on Performance Imptovement on a Manufacturing Task", Journal of Business, Vol 72, No. 3

Simanjuntak, Payaman, J. 2001. Ekonomi Sumber Daya Manusia. Lembaga Penerbit. Fakultas Ekonomi Universitas Indonesia: Jakarta.

Singh-Sengupta, Sunita, 1997, "Leadership: A Style or an Influence Process", Ijir, vol.32, no32 january, 265-286.

Soonhee Kim, 2002, "Participative Management and Job Satisfaction : Lesson for Management Leadership", Public Administration Review, Vol 62, No. 2, P. 231 241.

Sudarmadi.2007. Analisis pengaruh budaya organisasi Dan gaya kepemimpinan terhadap Kepuasan kerja dan kinerja Karyawan (Studi Empiris : Karyawan Administratif Universitas Semarang). Universitas Diponegoro.

Sugiyono. 2009. Metode Penelitian Bisnis. Bandung: Alfabeta.

Tett R. P., \& J. P Meyer, 1993, "Job Satisfaction Organizational Commitment, Turnover Intention, and Turnover: Path Analyses Based on Meta-Analytic Findings", Personnel Psychology 46(2): 259-93.

Trovik S. J \& McGiveren M. H., 1997, "Determinants of Organizational Performance", Management Decision, Volume 35, P.417-35.

Vigoda. 2006. Leadership style, organizational politics, and employees' performance An empirical examination of two competing models. Division of Public Administration and Policy, School of Political Sciences, University of Haifa, Haifa, Israel

Wagner J. A. III, 1994, "Participation's Effec on Performance and Satisfaction: A Reconsideration of Research Evidence", Academy of Management Review, 19 (2): 312-30.

Wallach E. J., 1983, "Individual and Organizations: The Culture Match", Training and Development Journal, 37: 2, 29-36.

Wiyono, D. G. (2011). Merancang Penelitian Bisnis dengan Alat Analisis SPSS 17.0 dan SmartPLS 2.0. Yogyakarta: Unit Penerbit dan Percetakan STIM YKPN.

Yukl, Gary. Leadership In Organization. Edisi keenam. Pearson International Edition. 